\title{
O CONCEITO DE JUSTIÇA AMBIENTAL NAS DISSERTAÇÕES E TESES BRASILEIRAS EM EDUCAÇÃO AMBIENTAL: UM ESTUDO PANORÂMICO E DE CONTEXTOS DE PRODUÇÃO
}

\author{
THE CONCEPT OF ENVIRONMENTAL JUSTICE IN THE \\ BRAZILIAN DISSERTATIONS AND THESIS \\ IN ENVIRONMENTAL EDUCATION: A PANORAMIC \\ AND PRODUCTION CONTEXTS STUDY \\ EL CONCEPTO DE JUSTICIA AMBIENTAL EN LAS \\ DISERTACIONES Y TESIS BRASILEÑAS EN EDUCACIÓN \\ AMBIENTAL: UN ESTUDIO PANORÁMICO \\ Y DE CONTEXTOS DE PRODUCCIÓN
}

Thaís Angeli ${ }^{1}$

Luiz Marcelo de Carvalho ${ }^{2}$ ${ }^{1}$ Universidade Estadual Paulista (UNESP), Rio Claro/SP, Brasil ${ }^{2}$ Universidade Estadual Paulista (UNESP), Rio Claro/SP, Brasil

Resumo Neste artigo, procuramos sistematizar alguns dados relativos ao contexto de produção de dissertações e teses brasileiras em educação ambiental que problematizam questões concernentes à justiça ambiental, bem como, analisar os contextos educacionais e temas de estudo privilegiados nesses trabalhos. Trata-se de uma pesquisa de natureza qualitativa, documental e do tipo "estado da arte", que está inserida no âmbito do Projeto Educação Ambiental no Brasil: análise da produção acadêmica - teses e dissertações (Projeto EArte). Nessa direção, foi possível observar que o primeiro trabalho em EA que problematiza o conceito de justiça ambiental foi publicado no ano de 2004 e que, nessa produção acadêmica que estabelece relações entre educação ambiental e justiça ambiental, ganham destaque as regiões Sudeste, Sul e Centro-Oeste e os programas de pós-graduação da área de Educação da UFMT, UFRJ e Furg. Também se verificou que as pesquisas analisadas se 
voltam para o contexto escolar e não escolar, tendo como objetivo central a busca por uma formação voltada à transformação social e justiça ambiental.

Palavras-chave: Educação ambiental; Justiça ambiental; Pesquisa.

Abstract In this article, we try to systematize some data about the context of production of Brazilian dissertations and theses on environmental education which problematize issues related to environmental justice, as well as to analyze the educational contexts and privileged study themes in these works. This is a qualitative, documentary and state-of-theart research, which is part of the Environmental Education Project in Brazil: analysis of academic production - theses and dissertations (EArte Project). In this sense, it was possible to observe that the first work on EA that problematized the concept of environmental justice was published in 2004 and that, in this academic production that establishes relations between environmental education and environmental justice, the Southeast, South and Midwest regions and the postgraduate programs of the Education area of UFMT, UFRJ and Furg can be highlighted. It was also observed that the analyzed research involves the school and non-school context, with the central objective being the search for a formation focused on social transformation and environmental justice.

Keywords: Environmental education; EnVironmental Justice; Research.

RESUMen En este artículo, buscamos sistematizar algunos datos relativos al contexto de producción de disertaciones y tesis brasileñas en educación ambiental que problematizan cuestiones relativas a la justicia ambiental, así como analizar los contextos educativos y temas de estudio privilegiados en esos trabajos. Se trata de una investigación de naturaleza cualitativa, documental y del tipo "estado del arte", que está inserta en el ámbito del Proyecto Educación Ambiental en Brasil: análisis de la producción académica - tesis y disertaciones (Proyecto EArte). En esa dirección, fue posible observar que el primer trabajo en EA que problematiza el concepto de justicia ambiental fue publicado en el año 2004 y que, en esa producción académica que establece relaciones entre educación ambiental y justicia ambiental, ganan destaque las regiones Sudeste, Sur y Centro-Oeste y los programas de postgrado del área de Educación de la UFMT, UFRJ y Furg. También se observó que las investigaciones analizadas se vuelven hacia el contexto escolar y no escolar, teniendo como objetivo central la búsqueda de una formación volcada a la transformación social y la justicia ambiental.

Palabras clave: Educación ambiental; Justicia ambiental; Investigación.

\section{INTRODUÇÃo}

Hoje em dia, vivenciamos os mais diversos problemas ambientais, sejam esses em nível local, regional, nacional ou global. Frente a esse quadro, Foladori (2001) afirma que, apesar 
de investigações sobre as causas antropogênicas das alterações da dinâmica natural apontarem para limites físicos da natureza, não podemos deixar de considerar que a relação que o ser humano estabelece com a natureza é diferente quando comparada à relação que outras espécies estabelecem com a natureza. Tal distinção se sustenta no fato de a sociedade humana ter peculiaridades que resultam em uma distinta apropriação histórica da natureza e dos meios de vida por diversas classes e grupos sociais. Essa distinta apropriação cria diferenças, tanto em relação à responsabilidade a respeito das transformações ambientais, quanto aos benefícios e prejuízos provenientes do funcionamento do ecossistema (FOLADORI, 2001).

Nesse complexo debate sobre os padrões de relação sociedade-natureza historicamente definidos, as causas que determinam esses padrões e as estratégias para a mitigação ou a solução dos problemas ambientais, Carvalho $(1989,2015)$ aponta para uma forte tendência entre os diferentes setores sociais em reconhecer o processo educativo como uma possibilidade de provocar mudanças e alterar o atual quadro de degradação ambiental.

Entretanto, cabe ressaltar que diferentes perspectivas de educação, de ser humano e de relação sociedade e natureza, engendram distintas propostas e tentativas de equacionamento dos problemas ambientais, bem como, diferentes concepções de educação ambiental (EA). Nesse sentido, ainda que seja possível reconhecer a existência de diversas vertentes do que se convencionou chamar de campo da educação ambiental crítica, partimos do entendimento de que, no contexto de uma EA que consideramos genuinamente crítica, a crítica está direcionada ao modelo de produção capitalista. Dessa forma, a EA crítica busca contextualizar e politizar o debate ambiental e problematizar as contradições dos modelos de desenvolvimento e de sociedade (LAYRARGUES; LIMA, 2014).

Assim, entre as questões que têm sido postas sob essa perspectiva, podemos destacar a necessidade de se considerar, nos discursos construídos no campo da EA, a relação que se pode estabelecer entre modelo de produção econômico, desigualdade social e desigualdade em relação aos efeitos das alterações ambientais antrópicas. Tal relação acaba gerando várias situações de injustiças socioambientais, que se caracterizam pelo fato de a sociedade destinar a maior carga dos danos ambientais provenientes do "desenvolvimento" às populações de baixa renda, aos grupos raciais discriminados, aos povos étnicos tradicionais, aos bairros operários e às populações marginalizadas e vulneráveis (RBJA, 2001).

A partir dessa problemática, podemos observar alguns esforços na construção do conceito $^{1}$ de justiça ambiental, o qual, para Acselrad (2010), envolve a noção de desigualdade na exposição à degradação ambiental, problematizando uma lógica em que a acumulação de riqueza se realiza tendo por base a penalização ambiental dos mais despossuídos. O autor afirma que justiça ambiental se caracteriza então em "um movimento de ressignificação da questão ambiental", resultante de "uma apropriação singular da temática do meio ambiente por dinâmicas sociopolíticas tradicionalmente envolvidas com a construção da justiça social" (ACSELRAD, 2010, p. 108).

\footnotetext{
Neste texto, iremos nos referir à justiça ambiental como um conceito, partindo da definição proposta pelo dicionário Houaiss de que conceito consiste em uma "ideia ou dito conciso; resumo, conceituação". Disponível em: $<$ http://houaiss.uol.com.br $>$. Acesso em: 29 set. 2017.
} 
Assim, tendo essa perspectiva como ponto de partida, é possível perceber que as reflexões e as discussões acerca desse conceito permitem revelar e compreender assimetrias de poder e esquemas de opressão social que perpetuam desigualdades socioambientais (COSENZA et al., 2014). Dessa maneira, alguns autores (COSENZA; MARTINS, 2012; PLÁCIDO; RODRIGUES, 2014; RIOS, 2015) vêm chamando a atenção para o papel que as práticas educativas relacionadas com o meio ambiente poderiam cumprir no sentido de fomentar tal discussão.

Para esses autores, a abordagem de questões relacionadas à justiça ambiental na EA reconhece a interdependência dos fatores econômicos, históricos, políticos, sociais e ambientais (PLÁCIDO; RODRIGUES, 2014). Dessa maneira, o diálogo entre EA e justiça ambiental abre possibilidades para se trabalhar elementos que incentivem e mobilizem a população para uma perspectiva mais ampla e crítica acerca da temática ambiental, abrindo possibilidades para que essa complexidade de fatores seja considerada.

Diante dessas possibilidades, Cosenza e Martins (2012) destacam que compreender melhor a articulação entre esses dois campos de conhecimento pode apontar caminhos para o fortalecimento de processos educativos que contextualizem e politizem o debate ambiental, problematizando as contradições dos modelos de desenvolvimento e de sociedade experimentadas em nível local e global.

Deste modo, entendemos que, entre os caminhos possíveis para aprofundar as nossas compreensões sobre propostas de EA que exploram questões de justiça ambiental, podemos considerar, tanto as experiências concretas que vêm sendo realizadas em diferentes contextos educacionais, envolvendo práticas pedagógicas de EA que consideram as perspectivas da justiça ambiental (COSENZA et al., 2014), como as análises de relatos de pesquisas que se voltam para tal articulação.

Quando consideramos a experiência brasileira, embora a pesquisa em EA seja recente, a sua produção acadêmica e científica, principalmente no contexto da pós-graduação no país, é numericamente surpreendente e bastante significativa, tanto no que diz respeito à diversidade das temáticas e problemas de investigação que têm sido eleitos, quanto no que se refere às perspectivas teóricas e metodológicas que têm orientado as investigações (FRACALANZA et al., 2008; CARVALHO; TOMAZELLO; OLIVEIRA, 2009; CARVALHO, 2015).

Nesse sentido, a análise dos textos de pesquisa que têm sido construídos pelos(as) pesquisadores(as) pode ser vista como um caminho significativo para a compreensão dos discursos que temos construído sobre as relações, possibilidades e limites da EA, no que se refere aos diferentes aspectos da temática ambiental. Além disso, análises dessa natureza também possibilitam a compreensão dos caminhos de construção do próprio campo de conhecimento da educação ambiental.

Considerando os pressupostos apresentados, o trabalho de mestrado da primeira autora deste artigo caminha na direção das pesquisas de estado da arte, voltando-se para a análise de relatos de pesquisa em EA, na forma de teses e dissertações brasileiras, que problematizam o conceito de justiça ambiental. Dessa forma, os objetivos da referida pesquisa 
foram caracterizar o contexto de produção desses trabalhos e explorar possíveis significados e sentidos sobre as relações entre educação ambiental e justiça ambiental propostas pelos pesquisadores e pesquisadoras em EA no Brasil (ANGELI, 2017). ${ }^{2}$

Guardadas tais características, a pesquisa de mestrado desenvolvida vincula-se diretamente com o esforço e tentativa de uma equipe bem ampla de pesquisadores(as) que vêm desenvolvendo o projeto Educação Ambiental no Brasil: análise da produção acadêmica - teses e dissertações (Projeto EArte). Essa tentativa de reunir de forma sistematizada a produção acadêmica brasileira em EA vem sendo desenvolvida desde 2008, tendo como principais objetivos a recuperação e a constituição de um acervo das dissertações e teses em EA desenvolvidas no Brasil ao longo dos anos e a realização de estudos descritivos e analíticos acerca dessa produção.

Nessa direção, este artigo, que sistematiza parte dos resultados e reflexões gerados a partir da dissertação de mestrado da primeira autora, foi pautado pelas seguintes questões de pesquisa: Que características, do ponto de vista da base institucional das pesquisas (TEIXEIRA, 2008) (ano de conclusão, localização geográfica, programa de pós-graduação, instituição de ensino superior, orientação e grupo de pesquisa), são predominantes no conjunto das teses e dissertações em EA que exploram o conceito de justiça ambiental? Que contextos educacionais e temas de estudo têm sido privilegiados pelos pesquisadores e pesquisadoras em suas investigações? Que objetivos e intenções, no que se refere a questões relacionadas à justiça ambiental, motivam essas pesquisas? ${ }^{3}$

Dessa forma, procuramos sistematizar, no presente texto, dados relativos ao contexto de produção dos trabalhos que estabelecem uma relação direta entre processos de EA e o conceito de justiça ambiental, sendo esses trabalhos conclú́dos no Brasil no período de 1981 a $2014^{4}$ e catalogados no Banco de Teses e Dissertações do Projeto EArte. Portanto, buscamos traçar um quadro panorâmico mais amplo do conjunto dessa produção.

\section{AsPectos Metodológicos e PROCEDIMENTOS DE PESQUiSA}

Este trabalho adota a abordagem qualitativa e consiste em uma pesquisa documental, tendo como objeto de investigação dissertações e teses em EA nas quais o conceito de justiça ambiental é problematizado. Além disso, ao considerarmos o fato de que esta pesquisa se volta para teses e dissertações, e que grande parte da produção científica é decorrente de programas de pós-graduação ou está relacionada a esses programas, podemos caracterizar a investigação como sendo uma pesquisa do tipo "estado da arte" (MEGID NETO; CAR-

2 Processo no. 2015/20352-4, Fundação de Amparo à Pesquisa do Estado de São Paulo - FAPESP.

3 Ano de conclusão, localização geográfica, programa de pós-graduação, instituição de ensino superior, orientação, contexto educacional e tema de estudo consistem em descritores utilizados no Projeto EArte, as suas especificações podem ser consultadas no site do Projeto. Disponível em: < $\underline{\text { http://www.earte. }}$ net/?page=projeto-descritores $>$. Acesso em: 25 fev. 2019.

4 Foram analisados trabalhos publicados entre 1981 e 2014 em razão de 1981 ser o ano dos primeiros trabalhos cadastrados no Banco de Teses e Dissertações do Projeto EArte e 2014 ser o ano anterior ao ingresso da pesquisadora no mestrado. 
VALHO, 2018), a qual também está inserida no âmbito de uma pesquisa mais ampla dessa natureza, intitulada Educação Ambiental no Brasil: análise da produção acadêmica-teses e dissertações (Projeto EArte).

O Projeto EArte é um projeto interinstitucional que procura reunir de forma sistematizada a produção acadêmica brasileira de teses e dissertações que têm como foco de investigação a relação entre o processo educativo e a temática ambiental. Desse modo, utilizamos como fonte para a identificação dos trabalhos que compõem o corpus documental desta pesquisa o Banco de Teses e Dissertações sistematizado pelo Projeto EArte, ${ }^{5}$ no qual se encontravam cadastradas, no período em que se deu a seleção dos trabalhos, 2.880 teses e dissertações.

Para o levantamento inicial das pesquisas em EA que, de alguma forma, se aproximavam do conceito de justiça ambiental, escolhemos justiça como o termo de busca para o levantamento das teses e dissertações no Banco EArte. Após leituras recorrentes das fichas dos 67 trabalhos encontrados, as quais incluíam os seus respectivos títulos, resumos e palavras-chave, observamos que expressões relacionadas à justiça ambiental estavam presentes em 26 trabalhos, que foram, portanto, selecionados. Nesses trabalhos, além do termo justiça ambiental, também foram identificadas as seguintes expressões: justiça socioambiental, justiça social e ambiental, injustiça ambiental, injustiças ambientais, injustiça socioambiental e justiça social, econômica e ambiental.

Todavia, conforme referido na introdução, a presente pesquisa se propôs a analisar teses e dissertações defendidas no período de 1981 a 2014 e, em razão de o Banco EArte não incluir, no período em que a seleção das teses e dissertações foi realizada, as pesquisas concluídas nos anos de 2010, 2013 e 2014, esses trabalhos foram selecionados por intermédio de buscas na Biblioteca Digital Brasileira de Teses e Dissertações (BDTD). ${ }^{6}$

Nesse processo, considerando que a BDTD não disponibiliza somente teses e dissertações em EA, mas em diversas áreas do conhecimento, primeiramente localizamos os trabalhos que abordavam o conceito de justiça ambiental, utilizando como termos de busca as expressões que foram encontradas nos 26 trabalhos selecionados por meio do Banco EArte. Por intermédio desse procedimento, localizamos 35 trabalhos que traziam o conceito de justiça ambiental, os quais foram analisados por meio da leitura das fichas disponibilizadas no sistema, procurando identificar, com base nos mesmos critérios adotados pela equipe do EArte, ${ }^{7}$ os trabalhos que tinham como foco processos relacionados com EA. Sendo assim, de acordo com o processo descrito, foram selecionados oito trabalhos através da busca na BDTD, que, somados aos já selecionados pela busca no Banco EArte, resultaram em um conjunto total de 34 teses e dissertações.

5 Disponível em: < http://www.earte.net>. Acesso em: 23 mar. 2015.

6 A BDTD consiste em um portal de busca que tem como objetivo reunir as teses e dissertações defendidas em todo o país e por brasileiros no exterior. O Banco foi concebido e é mantido pelo Instituto Brasileiro de Informação em Ciência e Tecnologia (IBICT) e teve o seu lançamento oficial no final do ano de 2002. Disponível em: $<$ http://bdtd.ibict.br $>$. Acesso em: 10 abr. 2015.

7 Os critérios para a seleção de dissertações e teses em EA utilizados pelo Projeto EArte podem ser consultados

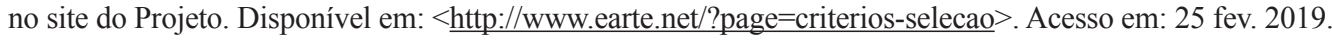


Com esse conjunto de trabalhos, demos início à leitura dos trabalhos completos, processo pelo qual 12 trabalhos foram excluídos das análises em razão de: não ser possível localizar o texto completo; o conceito de justiça ambiental não aparecer em momento algum durante todo o texto, ou ser citado apenas uma vez; ou o referido conceito não ser problematizado, considerando a ênfase que os autores e autoras deram a este ao longo de seus textos. Além disso, um trabalho que não constava nos bancos de dados consultados foi adicionado às análises em razão de atender aos critérios de seleção estipulados. Dessa forma, apresentamos no APÊNDICE A, o corpus documental desta pesquisa, constituído por 23 trabalhos em EA, sendo 18 dissertações de mestrado e cinco teses de doutorado nas quais o conceito de justiça ambiental é problematizado.

AS DISSERTAÇÕES E TESES EM EDUCAÇÃO AMBIENTAL QUE PROBLEMATIZAM O CONCEITO DE JUSTIÇA AMBIENTAL

Após a delimitação do corpus documental desta investigação, constituído por 23 dissertações e teses em educação ambiental nas quais questões relativas à justiça ambiental foram problematizadas, procuramos caracterizar esses trabalhos tendo como base os seus contextos de produção, contextos educacionais e temas de estudo privilegiados, bem como, os objetivos e intenções dos pesquisadores e pesquisadoras em EA no que se refere ao conceito de justiça ambiental. Sendo assim, a seguir, apresentaremos os resultados das análises que foram desenvolvidas.

\section{DISTRIBUIÇÃO TEMPORAL E GEOGRÁFICA}

Entre os diferentes aspectos voltados para o contexto de produção dos trabalhos, procuramos sistematizar os dados relacionados à distribuição temporal e geográfica das teses e dissertações que se voltaram para o foco desta pesquisa, ou seja, o número de trabalhos publicados ao longo dos anos, bem como, as regiões e Estados brasileiros nos quais esses trabalhos foram desenvolvidos.

Em relação à distribuição temporal das teses e dissertações analisadas, na Figura 1 procuramos indicar a quantidade de trabalhos concluídos, ano a ano, durante o período de 1981 a 2014 e, concomitantemente, a variação no número de trabalhos no decorrer desse período.

Pelos dados sistematizados na Figura 1, podemos observar que o primeiro trabalho em EA registrado nos bancos de teses e dissertações pesquisados por nós e que problematiza o conceito de justiça ambiental foi publicado no ano de 2004. Além disso, o trabalho em questão ( $\operatorname{Tr} 2)$ também foi o primeiro a citar o termo, considerando que não foram localizados trabalhos mais antigos do que esse nas etapas anteriores à definição do corpus documental definitivo desta pesquisa. A Figura 1 ainda ilustra que, a partir dessa primeira publicação, a distribuição temporal se manteve relativamente estável, não havendo grandes picos ao longo dos anos. 
Figura 1 - Distribuição temporal das teses e dissertações brasileiras em educação ambiental, publicadas de 2004 a 2014, nas quais questões relativas à justiça ambiental foram problematizadas.

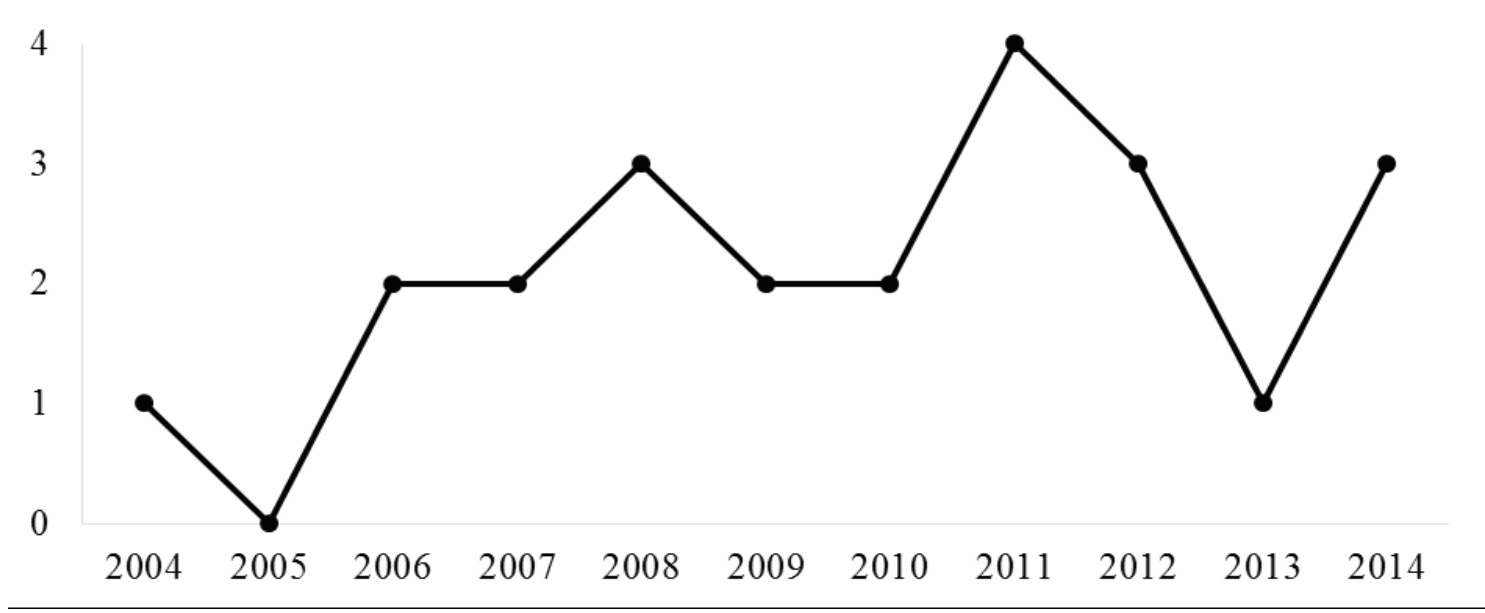

Fonte: Elaborada pela autora.

Um evento que notadamente marcou a introdução do conceito de justiça ambiental nos debates ambientalistas no Brasil foi o Colóquio Internacional sobre Justiça Ambiental, Trabalho e Cidadania, realizado na Universidade Federal Fluminense, em setembro de 2001. De acordo com Herculano (2008), essa foi possivelmente a primeira iniciativa de cunho acadêmico e político a se organizar no Brasil para discutir aspectos relacionados à proposta de justiça ambiental. Nessa ocasião, foi criada a Rede Brasileira de Justiça Ambiental (RBJA) e redigido o seu Manifesto de Lançamento.

Dessa forma, considerando a importância que o referido evento, ocorrido no final de 2001, teve no início de reflexões acerca da temática no país, entendemos ser possível relacioná-lo com o fato de o primeiro trabalho em EA que problematiza o conceito de justiça ambiental ter sido concluído em 2004. Contudo, contrariamente ao que se poderia esperar, é oportuno destacar que apenas nove dos 23 trabalhos analisados fizeram menção ao evento, ao Manifesto ou à RBJA $(\operatorname{Tr} 4, \operatorname{Tr} 5, \operatorname{Tr} 7, \operatorname{Tr} 9, \operatorname{Tr} 10, \operatorname{Tr} 18, \operatorname{Tr} 19, \operatorname{Tr} 27$ e $\operatorname{Tr} 28)$.

Já em relação à distribuição geográfica das teses e dissertações analisadas, na Figura 2 procuramos indicar em quais regiões e Estados brasileiros esses trabalhos foram desenvolvidos.

De acordo com a Figura 2, é possível observar que oito trabalhos foram desenvolvidos na região Sudeste do país, sendo seis no Rio de Janeiro (RJ) e dois em São Paulo (SP); sete trabalhos foram desenvolvidos na região Sul, no Estado do Rio Grande do Sul (RS); seis trabalhos foram desenvolvidos na região Centro-Oeste, no Estado do Mato Grosso (MT); um trabalho foi desenvolvido na região Nordeste, no Estado da Paraíba (PB); e um trabalho foi desenvolvido na região Norte, no Estado do Pará (PA). Observamos que as regiões Sudeste, Sul e Centro-Oeste se destacam na produção acadêmica em EA que estabelece relações com a justiça ambiental. 
Figura 2 - Distribuição geográfica das teses e dissertações brasileiras em educação ambiental, publicadas de 2004 a 2014, nas quais questões relativas à justiça ambiental foram problematizadas.

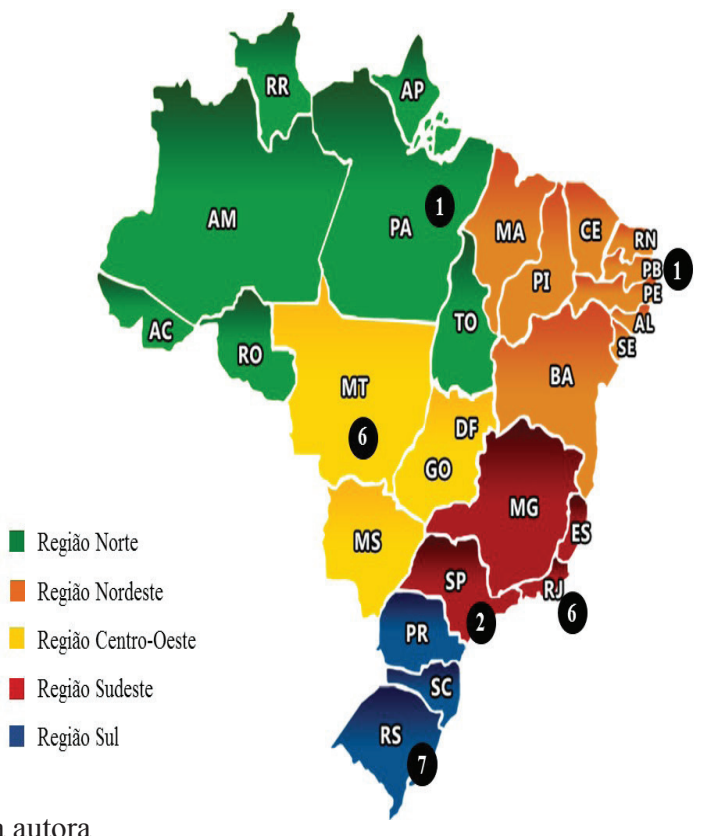

Fonte: Elaborada pela autora.

No que diz respeito à distribuição geral das pesquisas em EA no Brasil, Carvalho (2015) aponta para uma acentuada concentração dessas na região Sudeste, seguida pela região Sul, tanto em relação a artigos publicados em periódicos, quanto no que se refere à produção de teses e dissertações.

Além disso, quando analisamos a distribuição dos programas de pós-graduação no Brasil, também constatamos um grande predomínio da região Sudeste em relação às outras regiões do país. Atualmente, 1.781 programas de pós-graduação encontram-se cadastrados na região Sudeste, 833 na região Sul, 776 na região Nordeste, 318 na região Centro-Oeste e 197 na região Norte. $^{8}$

Entretanto, os dados da presente pesquisa apontam que, em relação à distribuição geográfica dos trabalhos em EA que problematizam o conceito de justiça ambiental, não há expressivas diferenças entre as regiões Sudeste, Sul e Centro-Oeste. Dessa forma, se considerarmos o número relativamente pequeno de programas de pós-graduação existentes na região Centro-Oeste e a grande concentração de pesquisas em EA desenvolvidas no Sudeste e Sul do Brasil, o destaque que a região Centro-Oeste, representada pelo Estado do Mato Grosso, assumiu no conjunto da produção acadêmica brasileira, analisada neste trabalho, foi bastante significativo.

Acreditamos que o número relativamente grande de pesquisas que se voltaram para as relações entre a EA e a justiça ambiental na região Centro-Oeste possivelmente apresenta

8 Dados obtidos por meio da Plataforma GEOCAPES - Sistema de Informações Georreferenciadas da CAPES. Disponível em: <http:/geocapes.capes.gov.br/geocapes2>. Acesso em: 30 nov. 2016. 
relação com o contexto socioeconômico e ambiental do Estado, bem como, com o contexto institucional de desenvolvimento dos trabalhos, o qual está associado à existência de grupos de pesquisa bastante sensíveis ao tema, conforme observaremos nos dados sistematizados no próximo item deste texto.

\section{CONTEXTO INSTITUCIONAL}

Entre os aspectos analisados, o contexto institucional das teses e dissertações é aquele que diz respeito aos programas de pós-graduação, instituições de ensino superior, orientação e grupos de pesquisa aos quais os trabalhos estavam vinculados.

Em relação aos programas de pós-graduação nos quais as pesquisas foram desenvolvidas, primeiramente, identificamos, de acordo com a classificação proposta pela CAPES, as grandes áreas e áreas básicas às quais esses programas estão associados. ${ }^{9}$ Dessa forma, pudemos considerar em quais áreas do conhecimento foram produzidos trabalhos em EA que problematizaram o conceito de justiça ambiental (Tabela 1).

Tabela 1 - Grande área e área básica dos programas de pós-graduação aos quais estavam vinculadas as teses e dissertações brasileiras em educação ambiental, concluídas no período de 2004 a 2014, que problematizam questões relativas à justiça ambiental, com o número de trabalhos pertencente a cada área e programa.

\begin{tabular}{ccc}
\hline Grande área & Área básica & Programa de pós-graduação \\
\hline \multirow{4}{*}{ Ciências Humanas (17) } & Educação (12) & $\begin{array}{c}\text { Educação (8) } \\
\text { Educação Ambiental (4) }\end{array}$ \\
\cline { 2 - 3 } & Psicologia (3) & $\begin{array}{c}\text { Psicossociologia de Comunidades e Ecologia } \\
\text { Social (3) }\end{array}$ \\
\cline { 2 - 3 } & Geografia (1) & Geografia (1) \\
\cline { 2 - 3 } & Sociologia (1) & Ciências Sociais (1) \\
\hline \multirow{3}{*}{ Multidisciplinar (5) } & $\begin{array}{c}\text { Ensino de Ciências e } \\
\text { Matemática (2) }\end{array}$ & $\begin{array}{c}\text { Ensino de Ciências (1) } \\
\text { Educação em Ciências e Saúde (1) }\end{array}$ \\
\cline { 2 - 3 } & $\begin{array}{c}\text { Ciências Ambientais } \\
(1)\end{array}$ & \begin{tabular}{c} 
Desenvolvimento e Meio Ambiente (1) \\
\cline { 2 - 3 }
\end{tabular} \\
\cline { 2 - 3 } & $\begin{array}{c}\text { Engenharia/ } \\
\text { Tecnologia/Gestão (1) }\end{array}$ & Geomática (1) \\
\cline { 2 - 3 } & $\begin{array}{c}\text { Meio Ambiente e } \\
\text { Agrárias (1) }\end{array}$ & $\begin{array}{c}\text { Gestão dos Recursos Naturais e } \\
\text { Desenvolvimento Local na Amazônia (1) }\end{array}$ \\
\hline Ciências Biológicas (1) & Ecologia (1) & Ecologia e Recursos Naturais (1) \\
\hline
\end{tabular}

*A classificação da Grande área e da Área básica às quais pertencem os programas de pós-graduação é proposta pela CAPES.

9 Dados obtidos por meio de buscas na Plataforma Sucupira. Disponível em: $<$ https://sucupira.capes.gov.br/ sucupira/public/consultas/coleta/programa/listaPrograma.jsf>. Acesso em: 26 set. 2016. 
Como podemos observar na Tabela 1, dos 23 trabalhos analisados, 17 foram desenvolvidos em programas de pós-graduação da grande área de Ciências Humanas, sendo 12 na área de Educação, três na Psicologia, um na Geografia e um na Sociologia. Cinco trabalhos foram desenvolvidos em programas de pós-graduação da grande área Multidisciplinar, sendo dois na área de Ensino de Ciências e Matemática, um nas Ciências Ambientais, um na Engenharia/Tecnologia/Gestão e um na área de Meio Ambiente e Agrárias. Por fim, um trabalho foi desenvolvido em um programa de pós-graduação da grande área de Ciências Biológicas, na área de Ecologia.

$\mathrm{O}$ fato de a maioria das teses e dissertações que se voltaram para o foco desta pesquisa terem sido desenvolvidas em programas de pós-graduação da área de Ciências Humanas, particularmente da Educação, parece acompanhar uma tendência esperada quando consideramos a relação entre a temática que estamos estudando e as diferentes áreas de conhecimento. Tal tendência também é observada nas pesquisas cadastradas no Banco EArte até o momento, evidenciando que a grande área de Ciências Humanas e a área básica de Educação abrigam o maior número de teses e dissertações em EA concluídas no Brasil (CARVALHO, 2015).

Em relação às instituições de ensino superior nas quais as pesquisas foram desenvolvidas, as 23 teses e dissertações analisadas estão distribuídas em 10 instituições, sendo que oito delas são federais e duas privadas. Além disso, os 23 trabalhos foram desenvolvidos sob a orientação de 14 pesquisadores(as) diferentes (Tabela 2).

$\mathrm{Na}$ Tabela 2, podemos observar que a Universidade Federal de Mato Grosso (UFMT) teve grande representatividade nas pesquisas analisadas, sendo responsável por seis delas, todas orientadas pela pesquisadora Michèle Sato, ${ }^{10}$ docente atualmente associada ao Programa de Pós-Graduação em Educação na UFMT. Além disso, a pesquisadora também foi responsável pela orientação de um trabalho desenvolvido na Universidade Federal de São Carlos (Ufscar), totalizando, assim, sete orientações dos trabalhos que fizeram parte do corpus documental desta investigação.

A pesquisadora Michèle Sato é uma das líderes do Grupo Pesquisador em Educação Ambiental, Comunicação e Arte (GPEA), grupo de pesquisa que atua no Pantanal, Cerrado e Amazônia Mato-grossense, trabalhando, principalmente, com comunidades tradicionais de indígenas, pantaneiros, ribeirinhos, quilombolas e seringueiros.

Em seguida da UFMT, podemos perceber que também ganham destaque a Universidade Federal do Rio de Janeiro (UFRJ) e a Universidade Federal do Rio Grande (Furg), responsáveis, respectivamente, por cinco e quatro das pesquisas analisadas. A representatividade da UFRJ está relacionada ao pesquisador Carlos Frederico Bernardo Loureiro, que orientou três dos cinco trabalhos desenvolvidos na instituição. Do mesmo modo, o pesquisador Carlos Roberto da Silva Machado foi responsável pela orientação de dois dos quatro trabalhos que foram desenvolvidos na Furg.

10 As informações referentes à Michèle Sato foram retiradas do Currículo Lattes da pesquisadora. Disponível em: <http://lattes.cnpq.br/9264997837722900>. Acesso em: 26 set. 2016. 
Tabela 2 - Relação das instituições nas quais foram desenvolvidas as teses e dissertações brasileiras em educação ambiental, concluídas no período de 2004 a 2014, que problematizam questões relativas à justiça ambiental, com os(as) pesquisadores(as) responsáveis pela orientação dos trabalhos.

\begin{tabular}{|c|c|c|c|c|}
\hline Instituiç̧ão & $\begin{array}{c}\text { Dependência } \\
\text { Administrativa* }\end{array}$ & Orientação & Trabalhos & $\begin{array}{c}\mathrm{N}^{\circ} \text {. de } \\
\text { trabalhos }\end{array}$ \\
\hline UFMT & $\mathrm{F}$ & Michèle Sato & $\begin{array}{l}\text { Tr} 4, \operatorname{Tr} 5, \operatorname{Tr} 6, \\
\operatorname{Tr} 9, \operatorname{Tr} 10, \operatorname{Tr} 11\end{array}$ & 6 \\
\hline \multirow{3}{*}{ UFRJ } & \multirow{3}{*}{$\mathrm{F}$} & $\begin{array}{l}\text { Carlos Frederico } \\
\text { Bernardo Loureiro }\end{array}$ & $\operatorname{Tr} 7, \operatorname{Tr} 8, \operatorname{Tr} 20$ & \multirow{3}{*}{5} \\
\hline & & $\begin{array}{c}\text { Tania Maria de Freitas } \\
\text { Barros Maciel }\end{array}$ & $\operatorname{Tr} 21$ & \\
\hline & & $\begin{array}{c}\text { Isabel Gomes } \\
\text { Rodrigues Martins }\end{array}$ & $\operatorname{Tr} 28$ & \\
\hline \multirow{3}{*}{ Furg } & \multirow{3}{*}{$\mathrm{F}$} & $\begin{array}{l}\text { Carlos Roberto da } \\
\text { Silva Machado }\end{array}$ & $\operatorname{Tr} 26, \operatorname{Tr} 27$ & \multirow{3}{*}{4} \\
\hline & & $\begin{array}{c}\text { Francisco Quintanilha } \\
\text { Véras Neto }\end{array}$ & $\operatorname{Tr} 15$ & \\
\hline & & $\begin{array}{l}\text { Maria do Carmo } \\
\text { Galiazzi }\end{array}$ & $\operatorname{Tr} 25$ & \\
\hline \multirow{2}{*}{ UFSM } & \multirow{2}{*}{$\mathrm{F}$} & $\begin{array}{c}\text { Pedro Roberto de } \\
\text { Azambuja Madruga }\end{array}$ & $\operatorname{Tr} 2$ & \multirow{2}{*}{2} \\
\hline & & $\begin{array}{l}\text { Adriano Severo } \\
\text { Figueiró }\end{array}$ & $\operatorname{Tr} 23$ & \\
\hline CUML & $\mathrm{P}$ & $\begin{array}{l}\text { Maria de Lourdes } \\
\text { Spazziani }\end{array}$ & $\operatorname{Tr} 1$ & 1 \\
\hline IFRJ & $\mathrm{F}$ & $\begin{array}{l}\text { Alexandre Maia do } \\
\text { Bomfim }\end{array}$ & $\operatorname{Tr} 17$ & 1 \\
\hline UFPA & $\mathrm{F}$ & $\begin{array}{l}\text { Marilena Loureiro da } \\
\text { Silva }\end{array}$ & $\operatorname{Tr} 12$ & 1 \\
\hline UFPB & $\mathrm{F}$ & $\begin{array}{l}\text { Francisco José Pegado } \\
\text { Abílio }\end{array}$ & $\operatorname{Tr} 22$ & 1 \\
\hline Ufscar & $\mathrm{F}$ & Michèle Sato & $\operatorname{Tr} 19$ & 1 \\
\hline Unisinos & $\mathrm{P}$ & Aloísio Ruscheinsky & $\operatorname{Tr} 18$ & 1 \\
\hline
\end{tabular}

*A letra $\mathrm{F}$ indica as instituições que são federais e a letra $\mathrm{P}$ as que são privadas. 
O pesquisador Carlos Frederico Bernardo Loureiro ${ }^{11}$ atualmente é docente associado aos Programas de Pós-Graduação em Educação e em Psicossociologia de Comunidades e Ecologia Social, ambos da Faculdade de Educação da UFRJ. É um dos líderes do grupo de pesquisa Laboratório de Investigações em Educação, Ambiente e Sociedade (LIEAS), o qual é constituído pelas seguintes linhas de pesquisa: construção do conhecimento em educação ambiental; educação ambiental e movimentos sociais; educação ambiental em unidades de conservação; educação ambiental na escola; e mediações entre modelos de desenvolvimento e políticas públicas em ambiente e educação.

Já o pesquisador Carlos Roberto da Silva Machado, ${ }^{12}$ atualmente, é docente associado ao Programa de Pós-Graduação em Educação Ambiental na Furg, além de ser um dos líderes do Grupo de Pesquisa em Política, Natureza e Cidade e coordenar o Observatório dos Conflitos do Extremo Sul do Brasil, no qual a questão ambiental e urbana vem sendo mapeada, a partir de manifestações públicas. Os dois trabalhos que Machado orientou $\operatorname{Tr} 26$ e $\operatorname{Tr} 27$ - são de 2013 e 2014, respectivamente, o que pode estar relacionado com o enfoque que o pesquisador afirma estar procurando dar às suas pesquisas nos últimos anos, buscando avançar na relação entre (in) justiça social e ambiental na região do extremo sul do Brasil.

\section{Contexto educacional}

Conforme anunciado no início desta seção, procuramos levantar informações a respeito dos contextos educacionais e temas de estudo que foram privilegiados nas pesquisas analisadas. O contexto educacional de um trabalho, de acordo com os critérios de classificação utilizados pela equipe do EArte, se refere ao campo educacional abrangido pela pesquisa, tanto em relação aos trabalhos de campo, como em relação ao direcionamento das reflexões desenvolvidas pelos(as) pesquisadores(as). Nesse sentido, o contexto educacional de um trabalho pode ser classificado em: escolar, não escolar ou abordagem genérica do contexto educacional.

Dessa forma, com base no descritor utilizado no Projeto EArte, apresentamos os contextos educacionais para os quais se voltaram as dissertações e teses em educação ambiental nas quais o conceito de justiça ambiental foi problematizado (Tabela 3).

Considerando que o conceito de justiça ambiental surgiu dos movimentos sociais, ao analisarmos os contextos educacionais para os quais se voltaram os trabalhos avaliados, poderíamos esperar por uma predominância de pesquisas desenvolvidas em contexto não escolar. Entretanto, além de apenas duas pesquisas terem se voltado para movimentos sociais, conforme poderá ser visto no item seguinte, de acordo com os dados ilustrados na Tabela 3, é possível observar que praticamente não houve diferença entre o número de trabalhos desenvolvidos em contexto escolar e não escolar.

11 As informações referentes a Carlos Frederico Bernardo Loureiro foram retiradas do Currículo Lattes do

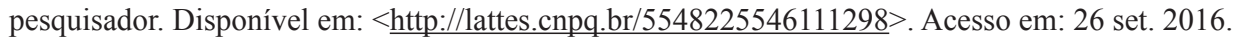

12 As informações referentes a Carlos Roberto da Silva Machado foram retiradas do Currículo Lattes do pes-

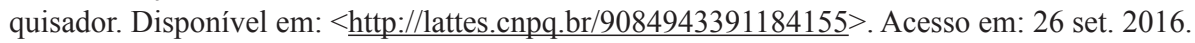


Tabela 3 - Contextos educacionais para os quais se voltaram as teses e dissertações brasileiras em educação ambiental, concluídas no período de 2004 a 2014, que problematizam questões relativas à justiça ambiental.

\begin{tabular}{|c|c|c|c|}
\hline $\begin{array}{l}\text { Contextos } \\
\text { educacionais }\end{array}$ & Níveis escolares & Trabalhos & $\begin{array}{c}N^{o} \text {. de } \\
\text { trabalhos }\end{array}$ \\
\hline Não escolar & - & $\begin{array}{l}\operatorname{Tr} 1, \operatorname{Tr} 2, \operatorname{Tr} 4, \operatorname{Tr} 5, \operatorname{Tr} 6, \\
\operatorname{Tr} 7, \operatorname{Tr} 10, \operatorname{Tr} 12, \operatorname{Tr} 19 \\
\quad \operatorname{Tr} 21, \operatorname{Tr} 26, \operatorname{Tr} 27\end{array}$ & 12 \\
\hline \multirow{4}{*}{ Escolar } & Ensino Fundamental II & $\operatorname{Tr} 17, \operatorname{Tr} 20, \operatorname{Tr} 22, \operatorname{Tr} 23$ & \multirow{4}{*}{11} \\
\hline & $\begin{array}{l}\text { Abordagem Genérica } \\
\text { dos Níveis Escolares }\end{array}$ & $\operatorname{Tr} 9, \operatorname{Tr} 11, \operatorname{Tr} 18$ & \\
\hline & Educação Superior & $\operatorname{Tr} 2, \operatorname{Tr} 15, \operatorname{Tr} 25$ & \\
\hline & Ensino Médio & $\operatorname{Tr} 22, \operatorname{Tr} 28$ & \\
\hline $\begin{array}{c}\text { Abordagem } \\
\text { genérica do contexto } \\
\text { educacional }\end{array}$ & - & $\operatorname{Tr} 8$ & 1 \\
\hline
\end{tabular}

*Alguns trabalhos abordaram mais de um contexto educacional ou nível escolar.

Dessa maneira, esta pesquisa sugere que os(as) pesquisadores(as) também têm se preocupado com a análise e construção de propostas e práticas pedagógicas de EA que abordam questões relativas à justiça ambiental dentro da escola. Nesse contexto, ainda na Tabela 3, podemos observar que o foco das pesquisas em EA que problematizaram questões relativas à justiça ambiental no contexto escolar está distribuído entre Ensino Fundamental II, Ensino Médio e Educação Superior. Três trabalhos, ainda, não especificaram um nível escolar particular para o direcionamento dos estudos, adotando, dessa maneira, uma abordagem genérica dos níveis escolares.

\section{TEMAS DE ESTUDO}

Além do contexto educacional, outro descritor utilizado pela equipe do EArte nas classificações das teses e dissertações em EA se refere ao tema de estudo, ${ }^{13}$ que consiste no tema principal para o qual se volta o foco do trabalho, estando geralmente, mas não necessariamente, vinculado ao seu objetivo de pesquisa.

13 No EArte, o tema de estudo pode ser classificado em: Currículos, Programas e Projetos; Processos e Métodos de Ensino e de Aprendizagem; Recursos Didáticos; Concepções/Representações/Percepções e Processos Cognitivos do Formador em EA; Concepções/Representações/Percepções e Processos Cognitivos do Aprendiz em EA; Comunicação; Políticas Públicas em EA; Organização da Instituição Escolar; Organização Não-Governamental; Organização Governamental; Trabalho e Formação de Professores/Agentes de EA; Movimentos Sociais/Movimento Ambientalista; Fundamentos em EA; e Outro. Os critérios de classificação utilizados no Projeto EArte podem ser consultados no site do Projeto. Disponível em: $<$ http://www. earte.net/?page=projeto-descritores $>$. Acesso em: 25 fev. 2019. 
Dessa maneira, com base nos critérios de classificação utilizados no Projeto EArte, sistematizamos os temas de estudo para os quais se voltaram as teses e dissertações analisadas nesta pesquisa. Em seguida, procuramos explorar, no âmbito de cada tema de estudo, os objetivos e intenções dos(as) pesquisadores(as) em EA no que se refere ao conceito de justiça ambiental (Quadro 1). Com isso, buscamos sistematizar as tendências de pesquisa nas teses e dissertações em EA que problematizam o conceito de justiça ambiental.

Quadro 1 - Objetivos e intenções dos(as) pesquisadores(as) em EA, de acordo com os temas de estudo levantados, no que se refere ao conceito de justiça ambiental, com base em teses e dissertações brasileiras em educação ambiental, concluídas no período de 2004 a 2014, que problematizam questões relativas à justiça ambiental.

\begin{tabular}{|c|c|c|}
\hline Temas de estudo & Trabalhos & $\begin{array}{c}\text { Objetivos e intenções relacionados à justiça } \\
\text { ambiental }\end{array}$ \\
\hline \multirow{3}{*}{$\begin{array}{l}\text { 1. Currículos, Programas e } \\
\text { Projetos }\end{array}$} & \multirow{3}{*}{$\begin{array}{l}\operatorname{Tr} 1, \operatorname{Tr} 8, \operatorname{Tr} 12, \\
\operatorname{Tr} 18, \operatorname{Tr} 20 \\
\quad \operatorname{Tr} 26\end{array}$} & $\begin{array}{l}\text { 1.1. Analisar se a abordagem adotada em } \\
\text { determinadas propostas de EA é influenciada } \\
\text { pelos contextos locais de degradação, riscos e } \\
\text { conflitos ambientais. }\end{array}$ \\
\hline & & $\begin{array}{l}\text { 1.2. Avaliar se determinadas propostas de } \\
\text { EA promovem transformações sociais e } \\
\text { enfrentamento das injustiças ambientais locais. }\end{array}$ \\
\hline & & $\begin{array}{l}\text { 1.3. Avaliar se determinadas propostas de EA } \\
\text { contribuem para a constituição de sujeitos que } \\
\text { busquem a justiça socioambiental. }\end{array}$ \\
\hline \multirow{4}{*}{$\begin{array}{l}\text { 2. Concepções/ } \\
\text { Representações/Percepções } \\
\text { e Processos Cognitivos do } \\
\text { Aprendiz em EA }\end{array}$} & \multirow{4}{*}{$\begin{array}{l}\operatorname{Tr} 1, \operatorname{Tr} 5, \operatorname{Tr} 10, \\
\operatorname{Tr} 15, \operatorname{Tr} 21\end{array}$} & $\begin{array}{l}\text { 2.1. Analisar o processo de constituição de } \\
\text { sujeitos que buscam a justiça socioambiental. }\end{array}$ \\
\hline & & $\begin{array}{l}\text { 2.2. Analisar representações de educandos } \\
\text { acerca de questôes relacionadas à justiça } \\
\text { socioambiental. }\end{array}$ \\
\hline & & $\begin{array}{l}\text { 2.3. Analisar percepções de educandos acerca } \\
\text { dos conflitos socioambientais locais. }\end{array}$ \\
\hline & & $\begin{array}{l}\text { 2.4. Buscar aproximações entre EA e justiça } \\
\text { ambiental, a partir de percepções de grupos } \\
\text { marginalizados. }\end{array}$ \\
\hline
\end{tabular}




\begin{tabular}{|c|c|c|}
\hline Temas de estudo & Trabalhos & $\begin{array}{c}\text { Objetivos e intenções relacionados à justiça } \\
\text { ambiental }\end{array}$ \\
\hline \multirow[t]{2}{*}{$\begin{array}{l}\text { 3. Processos e Métodos de } \\
\text { Ensino e de Aprendizagem }\end{array}$} & \multirow[t]{2}{*}{$\begin{array}{l}\operatorname{Tr} 11, \operatorname{Tr} 17 \\
\quad \operatorname{Tr} 22\end{array}$} & $\begin{array}{l}\text { 3.1. Construir e desenvolver estratégias } \\
\text { pedagógicas de EA que incentivem a } \\
\text { participação da comunidade escolar nos } \\
\text { processos decisórios acerca das questões } \\
\text { socioambientais. }\end{array}$ \\
\hline & & $\begin{array}{l}\text { 3.2. Propor processos e métodos de ensino } \\
\text { e aprendizagem em EA voltados para a } \\
\text { construção de justiça ambiental. }\end{array}$ \\
\hline \multirow{2}{*}{$\begin{array}{l}\text { 4. Movimentos Sociais/ } \\
\text { Movimento Ambientalista }\end{array}$} & \multirow{2}{*}{$\operatorname{Tr} 6, \operatorname{Tr} 19$} & $\begin{array}{l}\text { 4.1. Mapear os conflitos socioambientais } \\
\text { regionais. }\end{array}$ \\
\hline & & $\begin{array}{l}\text { 4.2. Analisar a história do movimento } \\
\text { ecológico, com os dilemas sociais relacionados. }\end{array}$ \\
\hline \multirow{2}{*}{$\begin{array}{l}\text { 5. Políticas Públicas em } \\
\text { EA }\end{array}$} & \multirow[b]{2}{*}{$\operatorname{Tr} 18, \operatorname{Tr} 27$} & $\begin{array}{c}\text { 5.1. Identificar limites e potencialidades da EA, } \\
\text { sob a perspectiva do enfrentamento da injustiça } \\
\text { ambiental, no contexto de licenciamentos } \\
\text { ambientais. }\end{array}$ \\
\hline & & $\begin{array}{l}\text { 5.2. Analisar a relação entre as orientações de } \\
\text { políticas públicas ambientais e as práticas de } \\
\text { EA que são desenvolvidas nas escolas, sob } \\
\text { a perspectiva da constituição de sujeitos que } \\
\text { busquem a justiça socioambiental. }\end{array}$ \\
\hline \multirow{2}{*}{$\begin{array}{l}\text { 6. Trabalho e Formação de } \\
\text { Professores/Agentes de EA }\end{array}$} & \multirow{2}{*}{$\operatorname{Tr} 20, \operatorname{Tr} 28$} & $\begin{array}{l}\text { 6.1. Analisar se a prática docente em EA é } \\
\text { influenciada pelos contextos locais de riscos e } \\
\text { conflitos ambientais. }\end{array}$ \\
\hline & & $\begin{array}{l}\text { 6.2. Explorar sentidos na constituição de uma } \\
\text { prática docente voltada à construção de justiça } \\
\text { ambiental. }\end{array}$ \\
\hline 7. Comunicação & $\operatorname{Tr} 9$ & $\begin{array}{l}\text { 7.1. Analisar se a interface entre a EA e a } \\
\text { comunicação é viável como propulsora de } \\
\text { transformação e justiça socioambiental. }\end{array}$ \\
\hline $\begin{array}{l}\text { 8. Concepções/ } \\
\text { Representações/Percepções } \\
\text { e Processos Cognitivos do } \\
\text { Formador em EA }\end{array}$ & $\operatorname{Tr} 4$ & $\begin{array}{l}\text { 8.1. Analisar as percepções do formador em } \\
\text { EA sob a perspectiva de uma formação dos } \\
\text { sujeitos por meio dos princípios da justiça } \\
\text { socioambiental. }\end{array}$ \\
\hline 9. Estado da Arte & $\operatorname{Tr} 25$ & $\begin{array}{l}\text { 9.1. Demonstrar os desafios para integrar a } \\
\text { produção de um programa de pós-graduação } \\
\text { em educação ambiental enquanto política } \\
\text { e estratégia institucional de EA, de modo a } \\
\text { contribuir para a efetiva consolidação da justiça } \\
\text { socioambiental regional. }\end{array}$ \\
\hline
\end{tabular}




\begin{tabular}{|c|c|c|}
\hline Temas de estudo & Trabalhos & $\begin{array}{c}\text { Objetivos e intenções relacionados à justiça } \\
\text { ambiental }\end{array}$ \\
\hline 10. Fundamentos em EA & $\operatorname{Tr} 23$ & $\begin{array}{c}\text { 10.1. Identificar e discutir as matrizes teóricas e } \\
\text { epistemológicas associadas às práticas docentes } \\
\text { em EA, entendendo a educação ambiental como } \\
\text { um instrumento de transformação social na } \\
\text { busca de justiça socioambiental. }\end{array}$ \\
\hline $\begin{array}{l}\text { 11. Organização } \\
\text { Governamental }\end{array}$ & $\operatorname{Tr} 7$ & $\begin{array}{c}\text { 11.1. Analisar conflitos e injustiças ambientais } \\
\text { envolvendo o uso público religioso em unidade } \\
\text { de conservação. }\end{array}$ \\
\hline 12. Recursos Didáticos & $\operatorname{Tr} 2$ & $\begin{array}{c}\text { 12.1. Construir e disponibilizar recurso } \\
\text { didático para a utilização na gestão de conflitos } \\
\text { socioambientais. }\end{array}$ \\
\hline
\end{tabular}

*Alguns trabalhos apresentaram mais de um tema de estudo, com base nos critérios de classificação utilizados.

Pelos dados sistematizados no Quadro 1, podemos observar as questões relativas à justiça ambiental que ganharam destaque no âmbito de cada tema de estudo trabalhado nas pesquisas analisadas. Dessa forma, é possível perceber grande variedade de objetivos e intenções dos pesquisadores e pesquisadoras em EA ao trabalharem com questões relativas à justiça ambiental. No entanto, alguns aspectos, aparentemente, ganharam destaque no conjunto de teses e dissertações consideradas.

Um aspecto que se destacou nas pesquisas foi a busca de aproximação entre educação ambiental e justiça ambiental, almejando uma formação voltada à transformação social e justiça ambiental (objetivos $1.2 ; 1.3 ; 2.1 ; 3.2 ; 5.2 ; 6.2 ; 7.1 ; 8.1 ; 10.1$ ), o que pode ser observado no seguinte excerto de um trabalho:

Neste capítulo, destacamos também os campos conceituais da Educação Ambiental (EA), que se faz como tema central de nossa pesquisa. Uma EA crítica, ancorada essencialmente em Paulo Freire, para se despedir da neutralidade pedagógica e assumir seu caráter transformador. Esta aliança entre a Educação Ambiental e a Justiça Ambiental, vem fortalecer a luta por uma sociedade mais justa, com dignidade, inclusão social, cuidado ambiental, respeito e cidadania (Tr10, p. 19).

Dessa maneira, na busca por uma formação voltada à justiça socioambiental, a maioria das pesquisas explorou o conceito por intermédio da relação entre a educação ambiental e o contexto local de degradação, riscos e, principalmente, de conflitos socioambientais (objetivos $1.1 ; 1.2 ; 2.3 ; 4.1 ; 6.1 ; 9.1)$. Tal abordagem sugere uma preocupação do campo da EA com a construção e o desenvolvimento de práticas contextualizadas à realidade socioambiental local. Essa preocupação vai ao encontro da necessidade exposta por Running-Grass (1995), de uma educação ambiental que considere as injustiças socioambientais locais, de maneira a contribuir para o seu enfrentamento por parte das comunidades impactadas. 
Nessa direção, podemos notar que diversas pesquisas que se propuseram a construir, desenvolver ou analisar propostas de EA, destacam a importância de essas práticas promoverem contribuições socioambientais para as comunidades envolvidas (objetivos 1.2; 3.1), como pode ser observado no objetivo geral de uma das pesquisas consideradas:

\begin{abstract}
Verificar/constatar se o desenvolvimento da proposta do NUDESE de Agricultura Urbana e Periurbana contribui para a garantia da Soberania Alimentar das famílias envolvidas, partindo do entendimento de que ela seja mais do que acesso aos alimentos, mas envolva as dimensões ambiental, social, política, econômica, ética, etc. no tocante à produção, consumo e distribuição dos alimentos (Tr26, p. 21).
\end{abstract}

Além disso, podemos perceber que algumas pesquisas que se propuseram a construir, desenvolver ou analisar propostas de EA, também destacam a importância de essas práticas contribuírem para a constituição de sujeitos que busquem a justiça socioambiental (objeti$\operatorname{vos} 1.3 ; 2.1 ; 5.2 ; 8.1)$, conforme mencionado no seguinte excerto:

\footnotetext{
Na maior parte dos domingos, logo após os estudos para o ENEM, o GOTA, agora já ampliado, se reúne na sorveteria em frente à escola avaliando no grupo o "como estamos o que estamos fazendo e construindo na direção da busca de justiça social e ambiental” (Tr1, p. 78).
}

A respeito desses dois últimos aspectos enfatizados nas pesquisas, Rios (2015) destaca que, além do fortalecimento das populações diretamente afetadas por situações de injustiça ambiental, a EA também deve preocupar-se com o fortalecimento discursivo da luta por justiça ambiental junto à população como um todo. A autora explica que, dessa maneira, busca-se construir uma percepção comum favorável às lutas contra injustiças ambientais, entendendo essas como violações aos direitos humanos e à sustentabilidade ambiental. Para a autora, tal abordagem cria um ambiente discursivo que dá visibilidade e legitimidade às demandas dessas lutas e contribui para o fortalecimento de sujeitos coletivos e de mecanismos de gestão democrática.

\title{
CONSIDERAÇões FINAIS
}

Conforme inicialmente exposto, procuramos sistematizar no presente texto dados relativos ao contexto de produção de teses e dissertações, publicadas no período de 1981 a 2014, que estabelecem uma relação direta entre processos de EA e o conceito de justiça ambiental. Nessa direção, foi possível observar, no que diz respeito ao ano de conclusão dos trabalhos analisados, que a primeira pesquisa em EA que problematiza o conceito de justiça ambiental foi publicada no ano de 2004 e que, a partir desse ano, a distribuição temporal dos trabalhos se manteve estável até 2014. Quanto à distribuição geográfica, pudemos perceber que as regiões Sudeste, Sul e Centro-Oeste destacam-se na produção acadêmica em EA que estabelece relações com a justiça ambiental. Já no que diz respeito ao contexto ins- 
titucional dos trabalhos analisados, a maioria dos trabalhos foi desenvolvida em programas de pós-graduação na área das Ciências Humanas, principalmente em três universidades, quais sejam, a UFMT, UFRJ e Furg.

As teses e dissertações analisadas se voltaram, tanto para o contexto escolar, como para o não escolar, e, no âmbito dos temas de estudo, foi possível perceber que os pesquisadores e pesquisadoras em EA, ao trabalharem com questões relativas à justiça ambiental, têm como objetivo a busca por uma formação voltada à transformação social e justiça ambiental. Nessa busca, a maioria das pesquisas explora o conceito por meio da relação entre a educação ambiental e o contexto local de degradação, riscos e, principalmente, de conflitos socioambientais, de maneira a contribuir com transformações socioambientais para as comunidades envolvidas e com a constituição de sujeitos que busquem a justiça socioambiental.

Dessa maneira, a partir dos resultados observados nesta pesquisa, acreditamos que a tentativa de explorar a relação entre EA e justiça ambiental poderia possibilitar a mobilização da população para uma perspectiva mais ampla e crítica acerca da temática ambiental, bem como, contribuir para o enfrentamento das injustiças socioambientais.

Nesse sentido, os resultados obtidos neste trabalho também permitem levantar outras questões que poderiam orientar futuras pesquisas com essa temática, as quais poderiam, por exemplo, investigar o panorama internacional das pesquisas em EA que exploram questões relacionadas à justiça ambiental, ou aprofundar as discussões quanto ao papel que a EA pode desempenhar na construção de justiça ambiental.

\section{REFERÊNCIAS}

ACSELRAD, Henri. Ambientalização das lutas sociais - o caso do movimento por justiça ambiental. Estudos Avançados, São Paulo, v. 24, n. 68, p. 103-119, 2010.

ANGELI, Thaís. Os significados de justiça ambiental nas pesquisas em educação ambiental: uma análise a partir de teses e dissertações brasileiras, 2017, 112 p. Dissertação (Mestrado em Educação) - Instituto de Biociências, Universidade Estadual Paulista, Rio Claro, 2017.

CARVALHO, Luiz Marcelo de. A temática ambiental e a escola de primeiro grau, 1989, 282 p. Tese (Doutorado em Educação) - Faculdade de Educação, Universidade de São Paulo, São Paulo, 1989.

CARVALHO, Luiz Marcelo de. Pesquisa em Educação Ambiental no Brasil: um campo em construção? 2015, 455 p. Tese (Livre Docência) - Instituto de Biociências, Universidade Estadual Paulista, Rio Claro, 2015. 
CARVALHO, Luiz Marcelo de; TOMAZELLO, Maria Guiomar Carneiro; OLIVEIRA, Haydée Torres de. Pesquisa em Educação Ambiental: panorama da produção brasileira e alguns de seus dilemas. Cadernos Cedes, Campinas, v. 29, n. 77, p. 13-27, 2009.

COSENZA, Angélica; FREIRE, Laísa Maria; ESPINET, Mariona; MARTINS, Isabel. Relações entre justiça ambiental, ensino de ciências e cidadania em construções discursivas docentes. Revista Brasileira de Pesquisa em Educação em Ciências, São Paulo, v. 14, n. 2, p. 89-98, 2014.

COSENZA, Angélica; MARTINS, Isabel. Os sentidos de "conflito ambiental" na educação ambiental: uma análise dos periódicos de educação ambiental. Ensino, Saúde e Ambiente, Niterói, v. 5, n. 2, p. 234-245, 2012.

FOLADORI, Guillermo. O desenvolvimento sustentável e a questão dos limites físicos. In: . Limites do desenvolvimento sustentável. Campinas: Editora Unicamp, 2001, p. 101-140.

FRACALANZA, Hilário; AMARAL, Ivan Amorosino do; MEDIG NETO, Jorge; EBERLIN, Thais Schiavinato. A Educação Ambiental no Brasil: panorama inicial da produção acadêmica. Ciências em Foco, Campinas, v. 1, n. 1, p. 1-14, 2008.

HERCULANO, Selene. O clamor por justiça ambiental e contra o racismo ambiental. InterfacEHS, São Paulo, v. 3, n. 1, p. 1-20, jan./abr. 2008.

LAYRARGUES, Philippe Pomier; LIMA, Gustavo Ferreira da Costa. As macrotendências político-pedagógicas da Educação Ambiental brasileira. Ambiente \& Sociedade, São Paulo, v. 17, n. 1, p. 23-40, jan./mar. 2014.

MEGID NETO, J.; CARVALHO, L. M. Pesquisas de estado da arte: fundamentos, características e percursos metodológicos. In: ESCHENHAGEN, M. L.; VÉLEZ-CUARTAS, G.; MALDONADO, C.; PINO, G. G. (Ed.). Construcción de problemas de investigación: diálogos entre el interior y el exterior. Medellin: Universidad Pontifica Bolivariana / Universidad de Antioquia, 2018, p. 97-113.

PLÁCIDO, Patrícia Oliveira; RODRIGUES, Jéssica Nascimento. Educação e Justiça Ambiental: diálogos possíveis. Revista Comunicação e Educação Ambiental, Rio de Janeiro, v. 4, n. 2, p. 44-62, jul./dez. 2014.

RBJA. Rede Brasileira de Justiça Ambiental. Manifesto de lançamento da Rede Brasileira de Justiça Ambiental, 2001. Disponível em: $<$ http://www.mma.gov.br/destaques/ item/8077-manifesto-de-lan\%C3\%A7amento-da-rede-brasileira-de-justi\%C3\%A7a-ambiental $>$. Acesso em: 3 set. 2016. 
RIOS, Natalia Tavares. Educação ambiental e direitos humanos: articulações teóricas a partir das categorias do movimento de Justiça Ambiental. In: ENCONTRO PESQUISA EM EDUCAÇÃO AMBIENTAL, 8., 2015, Rio de Janeiro. Anais... Rio de Janeiro: UNIRIO/ UFRRJ/UFRJ, 2015, p. 1-13.

RUNNING-GRASS. Environmental Education for Environmental Justice: a Three Circles Perspective. Journal of Multicultural Environmental Education, Sausalito, v. 2, n. 1, p. 4-18, 1995.

TEIXEIRA, Paulo Marcelo Marini. Pesquisa em Ensino de Biologia no Brasil (19722004): um estudo baseado em dissertações e teses, 2008, 227 p. Tese (Doutorado em Educação) - Faculdade de Educação, Universidade Estadual de Campinas, Campinas, 2008.

\section{APENDICE A}

Teses (T) e dissertações (D) brasileiras em educação ambiental, concluídas no período de 2004 a 2014, que problematizam questões relativas à justiça ambiental e compõem o corpus documental desta pesquisa.

\begin{tabular}{|c|c|c|c|}
\hline Código & $\mathbf{D} / \mathbf{T}$ & Autoria & Título \\
\hline $\operatorname{Tr} 1$ & $\mathrm{D}$ & $\begin{array}{l}\text { Desiree Albuquerque } \\
\text { Biasoli-Corrêa }\end{array}$ & Indícios da constituição do sujeito socioambiental \\
\hline $\operatorname{Tr} 2$ & $\mathrm{D}$ & $\begin{array}{l}\text { Enise Maria Bezerra } \\
\text { Ito Isaia }\end{array}$ & $\begin{array}{l}\text { Geoprocessamento e educação ambiental no } \\
\text { processo de gestão do conflito socioambiental do } \\
\text { Arroio Cadena, Santa Maria, RS }\end{array}$ \\
\hline $\operatorname{Tr} 4$ & $\mathrm{D}$ & $\begin{array}{l}\text { Fernanda de Arruda } \\
\text { Machado }\end{array}$ & $\begin{array}{c}\text { Cultura e natureza nos centros e periferias da } \\
\text { educação ambiental }\end{array}$ \\
\hline $\operatorname{Tr} 5$ & $\mathrm{D}$ & $\begin{array}{l}\text { Ivan César Corrêa do } \\
\text { Belém }\end{array}$ & $\begin{array}{l}\text { Mitos africanos e pantaneiros nos círculos de } \\
\text { aprendizagens ambientais }\end{array}$ \\
\hline Tr6 & $\mathrm{D}$ & Jonia Teresinha Fank & $\begin{array}{l}\text { Flores, cores e saberes do movimento ecológico de } \\
\text { Mato Grosso em frutificação na educação ambiental }\end{array}$ \\
\hline $\operatorname{Tr} 7$ & $\mathrm{D}$ & $\begin{array}{l}\text { Lara Moutinho da } \\
\text { Costa }\end{array}$ & $\begin{array}{c}\text { A Floresta Sagrada da Tijuca: estudo de caso de } \\
\text { conflito envolvendo uso público religioso de parque } \\
\text { nacional }\end{array}$ \\
\hline $\operatorname{Tr} 8$ & $\mathrm{D}$ & $\begin{array}{l}\text { Luiza Maria Abreu } \\
\text { de Mattos }\end{array}$ & $\begin{array}{c}\text { A avaliação de ações de educação ambiental: um } \\
\text { estudo exploratório no âmbito da gestão pública sob } \\
\text { uma perspectiva crítica }\end{array}$ \\
\hline $\operatorname{Tr} 9$ & $\mathrm{D}$ & $\begin{array}{l}\text { Maria Liete Alves } \\
\text { Silva }\end{array}$ & $\begin{array}{l}\text { Educação ambiental e a mídia impressa: uma leitura } \\
\text { pantaneira }\end{array}$ \\
\hline $\operatorname{Tr} 10$ & $\mathrm{D}$ & $\begin{array}{l}\text { Michelle Tatiane } \\
\text { Jaber da Silva }\end{array}$ & $\begin{array}{l}\text { Viagens ao mundo dos seringueiros pelo itinerário } \\
\text { da educação ambiental }\end{array}$ \\
\hline
\end{tabular}




\begin{tabular}{|c|c|c|c|}
\hline Código & $\mathbf{D} / \mathbf{T}$ & Autoria & Título \\
\hline $\operatorname{Tr} 11$ & $\mathrm{D}$ & $\begin{array}{l}\text { Ronaldo Eustáquio } \\
\text { Feitoza Senra }\end{array}$ & $\begin{array}{c}\text { Por uma contrapedagogia libertadora no ambiente } \\
\text { do quilombo Mata Cavalo }\end{array}$ \\
\hline $\operatorname{Tr} 12$ & $\mathrm{D}$ & $\begin{array}{l}\text { Alexandre Macedo } \\
\text { Pereira }\end{array}$ & $\begin{array}{c}\text { O programa de educação ambiental dos grandes } \\
\text { empreendimentos (Vale S/A) na Amazônia e as } \\
\text { implicações socioambientais nas comunidades do } \\
\text { entorno: o caso da Vila Bom Jesus no município de } \\
\text { Canaã dos Carajás }\end{array}$ \\
\hline $\operatorname{Tr} 15$ & $\mathrm{D}$ & $\begin{array}{l}\text { Clêncio Braz da } \\
\text { Silva Filho }\end{array}$ & $\begin{array}{c}\text { Educação ambiental transformadora e bacharelismo: } \\
\text { uma leitura a partir de Pierre Bourdieu }\end{array}$ \\
\hline $\operatorname{Tr} 17$ & $\mathrm{D}$ & $\begin{array}{l}\text { Marcio Douglas } \\
\text { Floriano }\end{array}$ & $\begin{array}{l}\text { Educação e meio ambiente na Baixada Fluminense: } \\
\text { uma proposta de educação ambiental crítica numa } \\
\text { escola municipal em Duque de Caxias-RJ }\end{array}$ \\
\hline $\operatorname{Tr} 18$ & $\mathrm{D}$ & Marco Antonio Pagel & $\begin{array}{l}\text { Políticas públicas e propósitos socioambientais: } \\
\text { educação ambiental no ensino público de Cáceres- } \\
\text { MT }\end{array}$ \\
\hline $\operatorname{Tr} 19$ & $\mathrm{~T}$ & $\begin{array}{l}\text { Michelle Tatiane } \\
\text { Jaber da Silva }\end{array}$ & $\begin{array}{l}\text { O mapeamento dos conflitos socioambientais de } \\
\text { Mato Grosso: denunciando injustiças ambientais e } \\
\text { anunciando táticas de resistência }\end{array}$ \\
\hline $\operatorname{Tr} 20$ & $\mathrm{D}$ & Natalia Tavares Rios & $\begin{array}{l}\text { Educação ambiental em escolas próximas ao polo } \\
\text { industrial de Campos Elíseos: a influência do } \\
\text { contexto industrial e do risco }\end{array}$ \\
\hline $\operatorname{Tr} 21$ & $\mathrm{D}$ & $\begin{array}{l}\text { Vania de Oliveira } \\
\text { Nagem }\end{array}$ & $\begin{array}{l}\text { O mapa como expressão de conflitos e mobilização } \\
\text { social: um caminho para a justiça ambiental? }\end{array}$ \\
\hline $\operatorname{Tr} 22$ & $\mathrm{D}$ & $\begin{array}{l}\text { Flávio José Rocha da } \\
\text { Silva }\end{array}$ & $\begin{array}{l}\text { O teatro do oprimido como instrumento para a } \\
\text { educação ambiental }\end{array}$ \\
\hline $\operatorname{Tr} 23$ & $\mathrm{D}$ & $\begin{array}{l}\text { Anna Christine } \\
\text { Ferreira Kist }\end{array}$ & $\begin{array}{l}\text { Concepções e práticas de educação ambiental: } \\
\text { uma análise a partir das matrizes teóricas e } \\
\text { epistemológicas presentes em escolas estaduais de } \\
\text { ensino fundamental de Santa Maria-RS }\end{array}$ \\
\hline $\operatorname{Tr} 25$ & $\mathrm{~T}$ & $\begin{array}{l}\text { Washington Luiz dos } \\
\text { Santos Ferreira }\end{array}$ & $\begin{array}{l}\text { A poluição industrial no "mar de dentro" na } \\
\text { perspectiva da educação ambiental crítica e } \\
\text { transformadora }\end{array}$ \\
\hline $\operatorname{Tr} 26$ & $\mathrm{~T}$ & $\begin{array}{l}\text { Maria de Fátima } \\
\text { Santos da Silva }\end{array}$ & $\begin{array}{c}\text { Limites e contribuições da educação ambiental e da } \\
\text { agricultura de base agroecológica no extremo sul do } \\
\text { Brasil: o projeto de agricultura urbana e periurbana } \\
\text { em Rio Grande e São José do Norte (RS) }\end{array}$ \\
\hline $\operatorname{Tr} 27$ & $\mathrm{~T}$ & $\begin{array}{l}\text { Eugênia Antunes } \\
\text { Dias }\end{array}$ & $\begin{array}{c}\text { Desculpe o transtorno, estamos em obras para } \\
\text { melhor servi-lo! A educação ambiental no contexto } \\
\text { da apropriação privada da natureza no licenciamento } \\
\text { ambiental }\end{array}$ \\
\hline $\operatorname{Tr} 28$ & $\mathrm{~T}$ & $\begin{array}{l}\text { Angélica Cosenza } \\
\text { Rodrigues }\end{array}$ & $\begin{array}{c}\text { Justiça ambiental e conflito socioambiental na } \\
\text { prática escolar docente: significando possibilidades } \\
\text { e limites }\end{array}$ \\
\hline
\end{tabular}




\section{Dados dos AUTORES}

\section{Thaís Angeli}

Licenciada em Pedagogia e Ciências Biológicas. Bacharel em Ciência Biológicas. Mestra em Educação pelo Instituto de Biociências da Universidade Estadual Paulista. Rio Claro/ SP- Brasil. thais.angeli@hotmail.com

\section{Luiz Marcelo de Carvalho}

Licenciado em Ciência Biológicas e Doutor em Educação pela Universidade de São Paulo. São Paulo/SP- Brasil. Professor Livre-Docente em Educação Ambiental pelo Instituto de Biociências da Universidade Estadual Paulista. Rio Claro/SP - Brasil.1marcelo@rc.unesp.br

Submetido em: 29-10-2018

Aceito em: 15-3-2019 